\title{
The Recent Evolution of Global Tourism: Study Case - Switzerland
}

\author{
By Iulian Gole ${ }^{1}$, Raluca Georgiana Ladaru ${ }^{1}$, Carmen Valentina Radulescu ${ }^{1}$, \\ Svetlana Platagea Gombos ${ }^{1}$
}

\begin{abstract}
Among other negative economic and health outcomes, the global tourism industry is one of the most affected areas by the recent pandemic. A recent estimation shows that USD 1.3 trillion were lost in revenues, in 2020 only - which represents more than 11 times the loss suffered during the 2009 global economic crisis. It is by far the most the worst year in tourism history. As a direct consequence, many jobs are at risk, especially in small and medium-sized enterprises, in countries where tourism is the main economic component, the situation is quite dramatic. In this paper, we will analyse what happened in world large regions in the sector, what the perspectives to recovery are, and what are the rebound expectations and consumer confidence. We will also investigate the specificity of the tourism situation in Switzerland, where since the beginnings of the pandemic, the big cities and tourist locations have suffered greatly from the absence of foreign tourists. The cities close to the airports showed the strongest decreases in attendance. In contrast, those which are traditionally very touristy were only slightly affected by the decline in the number of foreign visitors.
\end{abstract}

Keywords: tourism evolution, pandemic effects, international tourism arrivals

\section{Introduction and Research Background}

Tourism (internal and international) is one of the economic sectors that have fully benefited in the last decades, especially by the popularization of the internet and transportation infrastructure development (Bran et al., 2020). The economic expansion of the sector had a continuously increasing path; a significant number of jobs were created over the years, investments in this area having a relatively short period of amortization (Radulescu et al., 2020). Overall, most local economies took advantage of tourism development (Cretu \& all, 2013). The travellers create additional demand for many other consumer goods and services, being responsible for stimulating the tertiary sector (services, trade, etc.). The policymakers, especially in the developing countries decided to focus and promote tourism because they saw there is a multiplier effect in term of creating new jobs, increasing export so a possibility to influence the balance of foreign exchange revenues (Tang \& all, 2007); these activities contributed directly to reduce poverty in the same area (Zhao \& Ritchie, 2007).

Many rural areas were developed especially due to rural tourism, local population enjoying the benefit of infrastructure and services progress (Dima et al., 2020). Undoubtedly, there are few unwished consequences also because of mass tourism (pollution, increasing prices, etc.) but overall the benefit is a net positive (Alecu and all, 2016). The permanent growing 
number in terms of profit has made from it a strategic industry, many countries being dependent by the evolution of the tourism sector (Negescu Oancea, et al., 2019).

World Travel \& Tourism Council estimated that in 2019, the travel \% tourism sector had a $3.5 \%$ growth, exceeding the rate of the global economy (which was $2.5 \%$ ) - the situation was similar during the whole period 2010-2019. According to the same data, between 2014 and $2019,25 \%$ of the new jobs were created by this sector which makes it an important factor for every government, employments generation being a desideratum for every politician.

2019 was an exceptional year for the travel and tourism industry, proved by very good indicators of economic performance: 8.9 USD trillion contributions to global GDP, which represents $10.3 \%$ of total GDP, $10 \%$ from the total new jobs created worldwide (around 330 million) originated from the sector. The tourists spent 1.7 trillion USD outside their countries, which represents $6.8 \%$ of total exports. A capital of almost 1 trillion USD was invested, the equivalent of $4.3 \%$ from total investment. All these numbers are showing a peak of performance for 2019; unfortunately, 2020 was a real catastrophe.

Further, we will have a look at what happened in the world's large regions in the sector, what the perspectives to recovery are, and what are the rebound expectations and consumer confidence. We will also investigate the specificity of the tourism situation in Switzerland, where since the beginnings of the pandemic, the big cities and tourist locations have suffered greatly from the absence of foreign tourists.

The first real signs appeared in late December 2019 and on 23 January 2020, a lockdown was imposed for the region of Wuhan, China. After a long period of hesitation, on 30 January, WHO declared the outbreak of global health emergency and on 11 March the official outbreak of the pandemic. On 20 April 2020, all worldwide destinations have introduced travel restrictions. On 1 of November 2020, still, 27\% of all destinations worldwide keep their borders completely closed for international tourism. Even if, meanwhile the few types of vaccine were produced, the situation is still difficult since not all countries had access to it and not all people. It is well known that until now, only the old generation, people having a serious medical record and few particular categories of employees could be vaccinated but these persons are not representing the majority of travellers at all.

\section{Methods}

By the means of descriptive and comparative analysis, we want to observe and exemplify with real data what is the size of the disaster, the difficulties that the tourism and travel industry encounters due to the Coronavirus, and what can be truly done to save this sector from bankruptcy. We start by analysing the tourism economic indicators like tourist arrivals, overnight stays, etc. by region in order to express the evolution in different areas of the world as well as the complexity that the tourism industry is confronting. We are looking also to the results of a survey to see the expectations regarding the recovery of the tourism industry

\section{Results}

The reality of disasters suffered by industry during 2020 can be easily observed in the next picture. Asia and the Pacific region collapsed from $+4 \%$ in 2019 to $-84 \%$ in 2020 . 
In real number, the region went from a pick of 360 million international tourist arrivals registered in 2019 to only 57 million, in 2020 - 300 million less. It is also the first region to enter into this spiral of losses.

The Middle East registered a shrink of international tourism of around $75 \%$. If in 2019 the region had $+8 \%$ international tourist arrivals (65 million), in 2020 only 16 million arrived in the area. Africa suffered also a $75 \%$ loss in terms of the number of international tourists, from 70 million in 2019 ( $+2 \%$ compared with 2018$)$ to a minimum of 18 million.

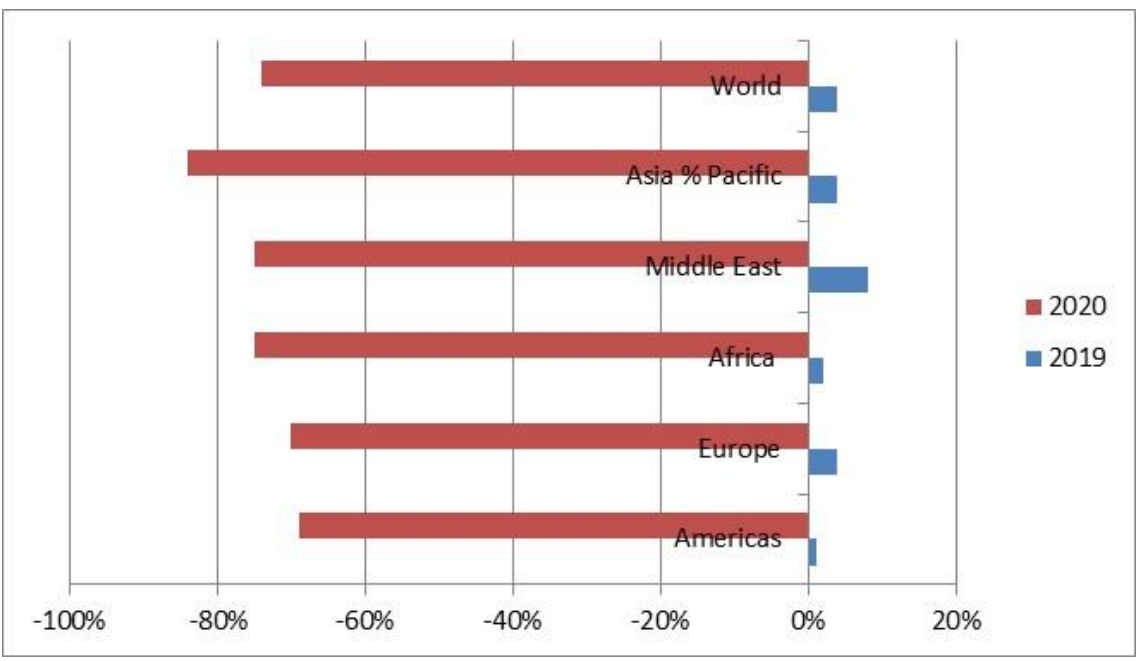

Picture 1. World tourist arrivals - 2020

Source: own representation, data from UNWTO.

Despite a certain relaxation policy and a short period of border opening during summer, Europe reached an extremely low level concerning the international arrivals, of $70 \%$. In absolute numbers, Europe suffered the most because 500 million fewer international tourists arrived in 2020, from 746 million in $2019(+4 \%)$ to 221 million in 2020. Due to a better last quarter of 2020, the Americas still registered a loss of 69\%, from 219 million international tourists in the previous year to 69 million.

The situation is something that the tourism and travel industry never saw. If we look at the performance of recent years, we can observe that the sector is facing an unprecedented economic downturn. Despite other international events that had negative consequences for the sector during the years (the SARS outbreak epidemic in 2004, the global economic crisis 2007-2009), nothing could be compared with what happened in 2020.

Table 1. Effects on international tourist arrivals

\begin{tabular}{|c|c|c|}
\hline 2003 - SARS & 2009 - Global Economic Crises & $2020-$ Covid 19 pandemic \\
\hline$-0,40 \%$ (-2 million) & $-4 \%(-37$ million $)$ & $-74 \%(-1.1$ billion $)$ \\
\hline
\end{tabular}

Source: collected data from UNWTO.

The same reality can be observed also if we have a look at the historical data. The travel \& tourism sector is today at the same level as 30 years ago. 


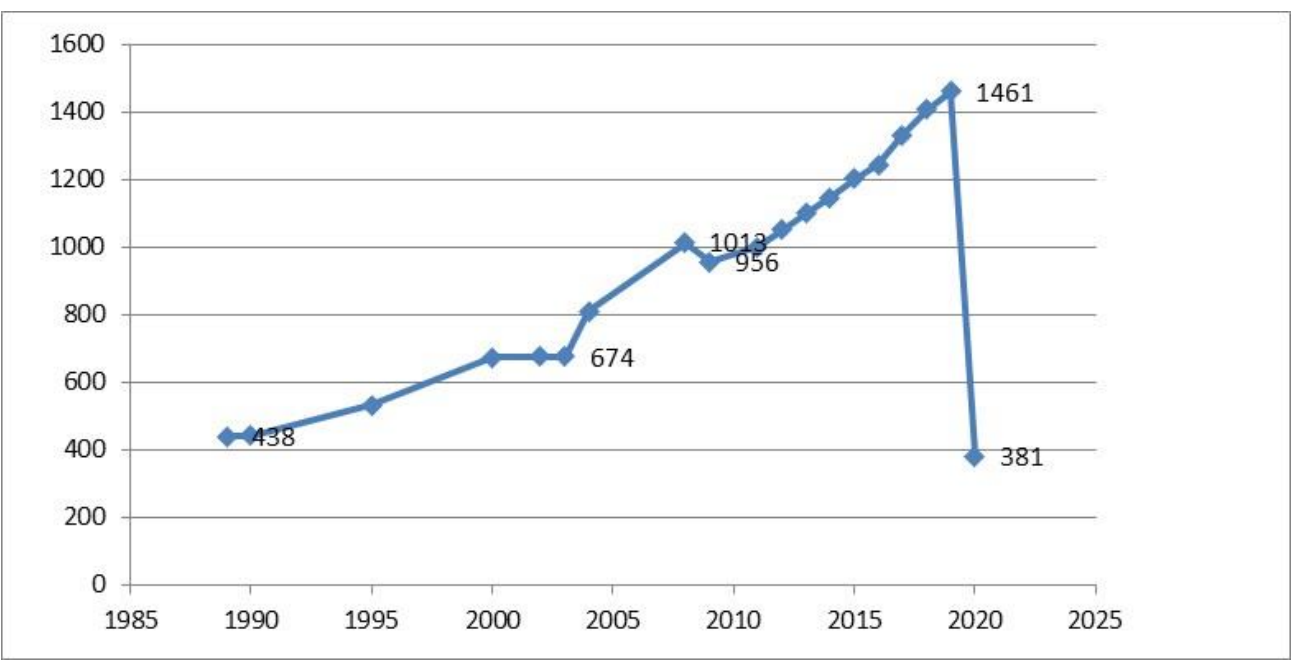

Picture 2. Evolution of tourist international arrivals in the last 3 decades (million).

Source: Own representation, data collected from different sources.

In his last report, UNWTO World Tourism Barometer, the fall in international travel is estimated as being 1.3 trillion USD in total export revenues, which is equivalent to 11 times the drop that the tourism and travel industry sector suffered during the 2009 economic crisis. Also, between 100 and 120 million direct tourism jobs were put at risk, unfortunately, most of them in small and medium-sized enterprises (more exposed to risks of economic shocks given the reduced amount of reserves), in countries heavily dependent on tourism revenue.

Because of the permanent and unpredictable evolution of the situation, while few countries decide to reopen their economies internally, many countries are deciding now to reintroduce heavy travel restrictions (Turkey and India just declare a new lockdown). Others are imposing mandatory tests, quarantines, or even a total closing of borders - all these measures will bring even more stress to the international travel sector. Despite the efforts done by the airline industry to protect the passengers or the availability of vaccines, still, the crisis is far from being over. The measures of testing and tracing will help to rebuild the traveller's confidence but it is a lot to be done in the area of vaccination certificates (it is not clear yet how the vaccine passports will be implemented and if all countries will accept). It is worthless to mention that the main enemy is the virus itself that proved to be one step ahead for every action that people took, by its mutations.

This level of uncertainty regarding the future recovery of the sector is also expressed by all people (professionals and clients). The travel restrictions will certainly slow the virus containment but at the same time will damage the economic environment, therefore besides the health security issue, people will confront financial problems.

A survey realised among the experts by UNWTO discloses that only $50 \%$ of them believe that the situation will improve during 2021, 50\% considering that things will go worse and the rebound will happen in 2022. 


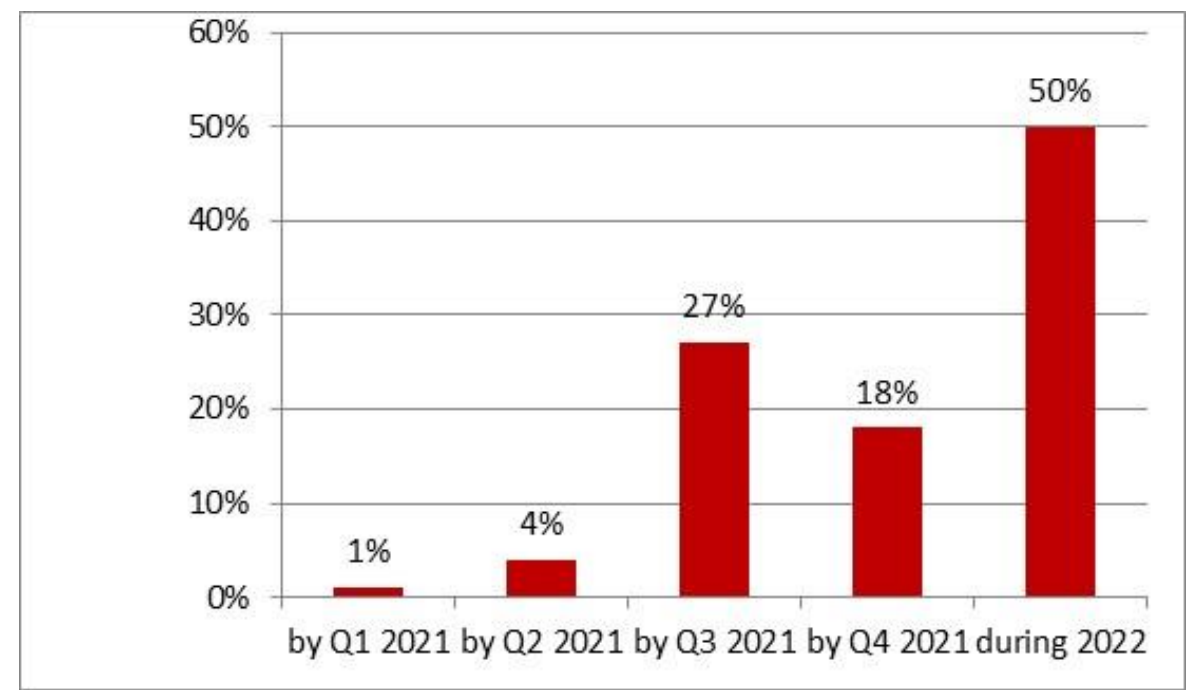

Picture 3. The expectations regarding the recovery of the tourism industry Source: Own representation, data collected by UNWTO, January 2021.

The results are quite not encouraging if we consider that in October 2020, $79 \%$ of people considered that the recovery will start in 2021. The general sentiment is rather pessimistic concerning the near future of the tourism sector.

When people are asked about when they expect that tourism will be at the same level as 2019 , most of them believe that it will take at least 2.5 years.

Table 2 . The expectations regarding the recovery of tourism industry to 2019 level

\begin{tabular}{|c|c|c|c|}
\hline 2021 & 2022 & 2023 & 2024 or later \\
\hline $1 \%$ & $15 \%$ & $43 \%$ & $45 \%$ \\
\hline
\end{tabular}

Source: data collected by UNWTO.

There are a few scenarios to be considered by the experts, when they are trying to foresee when the travel and \& tourism sector will recover but still we consider that it might be too early to predict. According to different data and perspectives, most of the specialists are considering that the industry will need between 2.5 and 4 years to come back on track.

It remains to be seen who accurate are these hypotheses and what the evolution will be but we can be sure that something changed in the traveller's behaviour recently, due to Covid-19, and this may continue. There is a tendency to travel closer to home; therefore the domestic tourism had a better performance, in many areas or countries. Many tourists opted for vacations where they could to be close to nature, open-air activities, and the rural and traditional area being most appreciated. These closer to home destinations become also interesting for travellers because of health and safety measures and the uncertainty of cancellation policies. Given the situation, last-minute booking became also a sort of new normality, many destinations being obliged to introduce travel restrictions from one day to another. 


\section{Study case - Switzerland}

Knew as a touristic destination preferred by many international tourists, Switzerland also faced the issues caused by the pandemic. The most affected were the big cities and tourist locations which have suffered greatly from the absence of foreign tourists and partly from that of Swiss customers. This situation has happened during the whole year of 2020, especially during the summer, the data concerning the winter season are not yet published. The cities close to the airports showed the strongest decreases in attendance. Contrary, those which are traditionally very touristy were only slightly affected by the decline in the number of foreign visitors during the summer months. In some cantons, the greater influx of Swiss customers even drastically increased overnight stays compared to the same period in 2019.

After an almost total paralysis of tourist activity linked to the coronavirus pandemic for almost three months from mid-March, Switzerland reopened its borders to all EU / EFTA states on June 15, precisely, at the start of the summer season, which allowed Swiss tourism to recover a little.

In April 2020, the decrease in the number of overnight stays nationwide compared to the same month of 2019 was $92 \%$, compared to only $26 \%$ in July. There are, however, huge differences between traditionally tourist regions and large cities. In the latter's hotels, the number of overnight stays fell by more than $60 \%$ in July and August, while it fell by only 20 to $30 \%$ in those of small and medium-sized canters during these two months. The situation was most favourable in touristic regions, with a decline not exceeding $10 \%$ over the same period. In addition, some regions have even recorded a significant increase in the number of customers, as the analysis at the different cantons reveals.

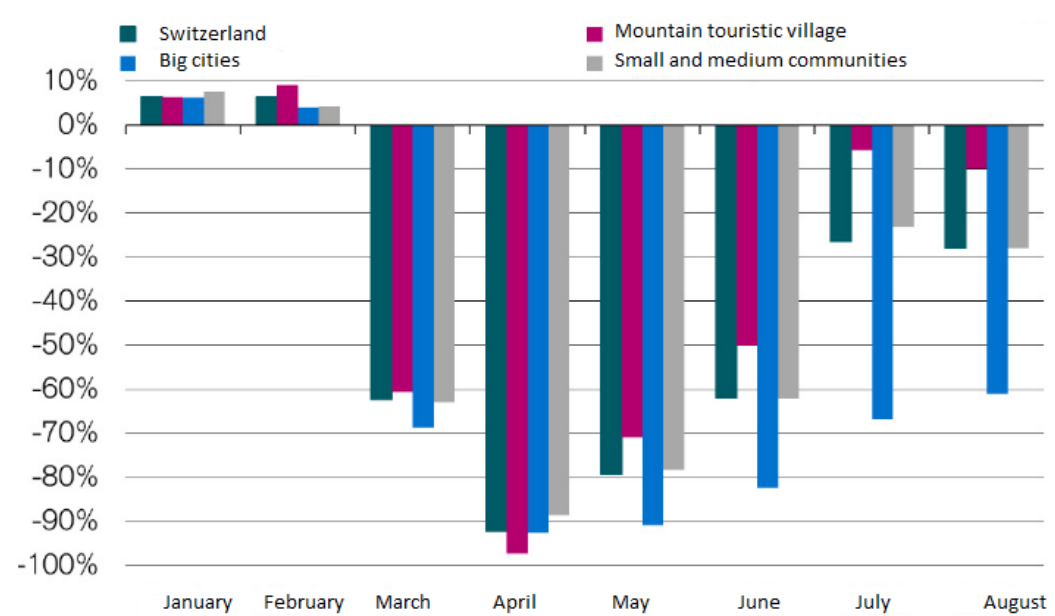

Fig. 4 Evolution of the number of overnight stays in 2020, compared to the same period of 2019

Source: Credit Suisse, OFS

Of the 26 Swiss cantons, seven even recorded a positive advancement regarding the overnight stays during the summer months (July and August 2020). Those of Appenzell 
Innerrhoden $(+27 \%)$ and Appenzell Ausserrhoden $(+15 \%)$ attracted mainly Frenchspeaking Swiss, who outnumbered other tourist groups. The cantons of Jura $(+28 \%)$ and Neuchâtel $(+24 \%)$ also benefited from the fact that many Swiss did not go on vacation abroad. Given the preference of many tourists for regions that are more remote and close to nature, their number has risen sharply in Ticino $(+8 \%)$ and Graubünden $(+7 \%)$ as well. On the other hand, in the three city cantons of Basel-City $(-57 \%)$, Zurich $(-70 \%)$ and Geneva $(-72 \%)$ the number of tourists diminished sharply. As for the cantons of Vaud ($31 \%)$, with the city of Lausanne, and Bern (-28\%), they were less strongly affected, as they both have renowned tourist regions which received more tourists than their principal cities. These large differences observed between tourist regions and cities can be explained by the composition of their respective clientele, which is closely linked to the countries of origin.

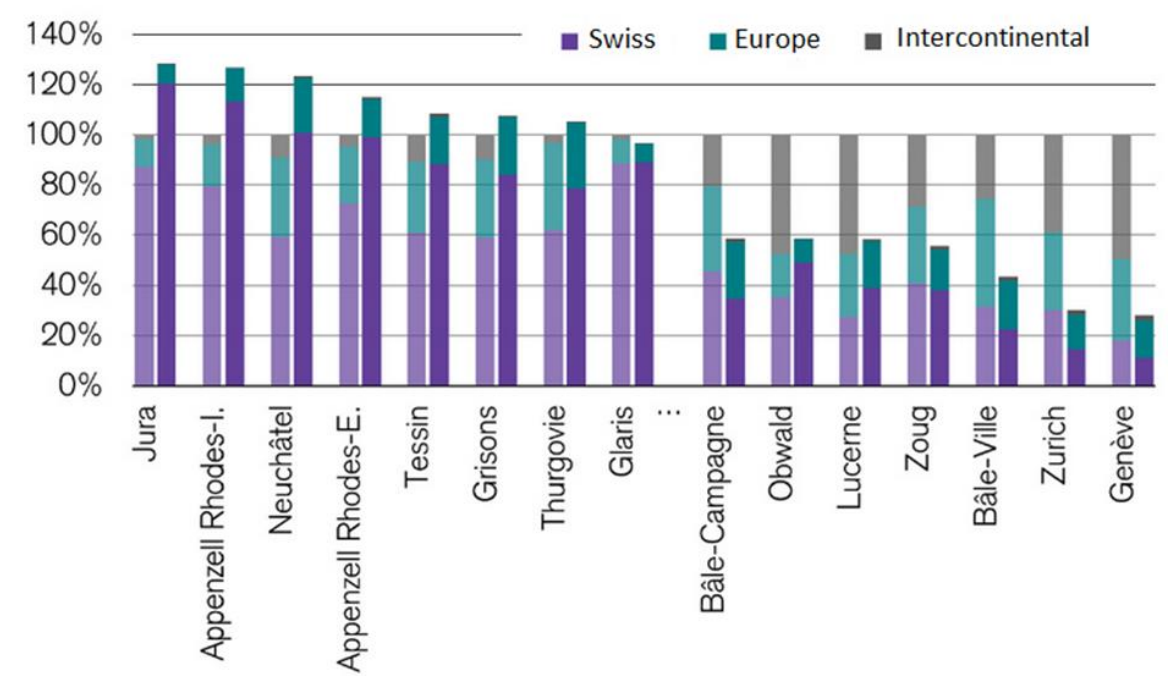

Fig. 5. Percentage of overnight stays according to the origin of customers, summer 2020 compared to summer 2019 July and August.

Source: Credit Suisse, OFS.

Among the cantons, few lost or gained more during the 2020 summer season. Still, we can distinguish easily those who are directly dependent on foreign tourists, especially nonEuropeans (picture 5). In summer 2019, major cities such as Basel, Zurich, and Geneva had mainly received foreign visitors. However, in 2020, the situation was a complete disaster regarding the non-European customer in July and August due to restrictions to entry into Switzerland. In addition, European and Swiss tourists were also significantly less likely to stay in large cities, due to the cancellation of conferences, trade, fairs, and major events, as well as by the drop in business tourism. In the touristic cantons, on the other hand, national customers more than offset the decline in demand from European and nonEuropean nationals.

Totally, in 2020, Switzerland had 12.000.231 tourists that spent 25.684.386 nights in hotels and other residences. $89.3 \%$ of the overnights were consumed by Swiss people. In 2019, Switzerland had 24.375.337 tourists who stayed 56.684.386 overnights -Swiss citizens 
representing $52.2 \%$ of the total (Office federal de la statistique, 2021). In conclusion, even if Switzerland had a dropping of $50 \%$ in terms of arrivals and overnights, the loss was adjusted by the Swiss inhabitants who decided to spend more vacation time inside the country (Peca, 2020).

\section{Conclusion}

The businesses from the travel \& tourism area suffered severe losses after the pandemic outbreak in January 2020, being one of the most affected industry sectors. Because of travel restrictions, the number of international arrivals diminished by $74 \%$ worldwide. Most of the countries struggling with this new reality; never, during the last decades, not even during the last economic crisis in 2007-2009, something similar has happened. The expectation about recovery are not encouraging, most of the people considering it will need between 2.5 and 4 years to go back on track. Nevertheless, few regions seemed to take advantage of the situation. Due to closeness to the big cities, the possibility of practicing open-air activities, rural tourism road trips, some specific destinations reached in the top of travellers preference, the number of overnights in 2020 being higher than in 2019, but still, these are the exception from the rule. The recovery solution (as well as in other linked sectors - events, sport, HORECA industry, aviation, etc.) is not in the hands of managers but rather in those of politicians who are responsible for imposing the restriction measures, medical doctors to treat the sick people, and health researchers who have to find rapidly the best cure.

\section{References}

Alecu Ioan Nicolae, Crețu Raluca Florentina, Ştefan Petrică, Crețu Romeo Cătălin, Beia Silviu Ionuț, Size of Unauthorized Tourism of the Danube Delta: Causes, Effects, Solutions, Agriculture and Agricultural Science Procedia, 2016, Volumul 10, nr. 1-2, pg. 511-518

Bran, F., Rădulescu, C. V., Bodislav, D. A., \& Burlacu, S. (2020). Environmental risks in the context of globalization. Economic Convergence in European Union, 350.

Credit Suisse, Office federal de la statistique, 2020, Evolution du nombre de nuitées par rapport au même mois de l'année précédente. Retrieved from https://www.allnews.ch/ckfinder/userfiles/images/ CS Tourisme Graph 01.jpg

Crețu Romeo Cătălin, Crețu, Raluca Florentina, Ştefan Petrică, Innovative and sustainable strategies in tourism and agritourism Romanian, Proceedings of the 7th International Management Conference "New Management for the New Economy, November 7th-8th, 2013, Bucharest, Romania, pag. 622-628, ISSN 2286-1440, ISSN-L 2286-1440

Dima, C., Burlacu, S., \& Buzoianu, O. A. C. (2020). Strategic Options for the Development of Ecotourism in the Danube Delta in the Context of Globalization. In SHS Web of Conferences (Vol. 74, p. 04005). EDP Sciences.

Negescu Oancea, M. D., Burlacu, S., Buzoianu, O. A. C., Mitrita, M., \& Diaconu, A. (2019). Strategic Options For The Development Of Ecoturism In The Dornelor County. The USV Annals of Economics and Public Administration, $19(1$ (29)), 21-28.

Office federal de la statistique, 2021, Hébergement touristique. Quoi de neuf?, Retrieved from https://www.bfs.admin.ch/bfs/fr/home/statistiques/tourisme/hebergement-touristique.html

Peca Servan, 2020, Le Temps, Le tourisme suisse affronte sa propre cherté. Retrieved from https://www.letemps.ch/economie/tourisme-suisse-affronte-propre-cherte 
Rădulescu, C. V., Burlacu, S., Bodislav, D. A., \& Bran, F. (2020). Entrepreneurial Education in the Context of the Imperative Development of Sustainable Business. European Journal of Sustainable Development, 9(4), 93-93.

SWI, 2020. Without foreign visitors, Switzerland's summer tourism season looks gloomy. Retrieved from https://www.swissinfo.ch/eng/covid-19-impact without-foreign-visitors--switzerland-s-summertourism-season-looks-gloomy/45829078

Tang, S.; Selvanathan, E.A.; Selvanathan, S. The Relationship between Foreign Direct Investment and Tourism: Empirical Evidence from China. Tour. Econ. 2007, 13, 25-39. Retrieved from https://journals.sagepub.com/doi/10.5367/000000007779784498

UNWTO, 2020: Worst Year in Tourism History with 1 Billion Fewer International Arrivals, Retrieved from https://www.unwto.org/news/2020-worst-year-in-tourism-history-with-1-billion-fewerinternational-arrivals

UNWTO, COVID-19 and tourism. 2020: A year in review, Retrieved from https://webunwto.s3.eu-west1.amazonaws.com/s3fs-public/2020-12/2020 Year in Review 0.pdf

Weibing Zhao \& J. R. Brent Ritchie (2007) Tourism and Poverty Alleviation: An Integrative Research Framework, Current Issues in Tourism, 10:2-3, 119-143, DOI: 10.2167/cit296.0

World Travel \& Tourism Council, 2020, Economic Impact Report, Retrieved from https://wttcweb.on.uat.co/Research/Economic-Impact. 